$$
\text { Entrevista }
$$

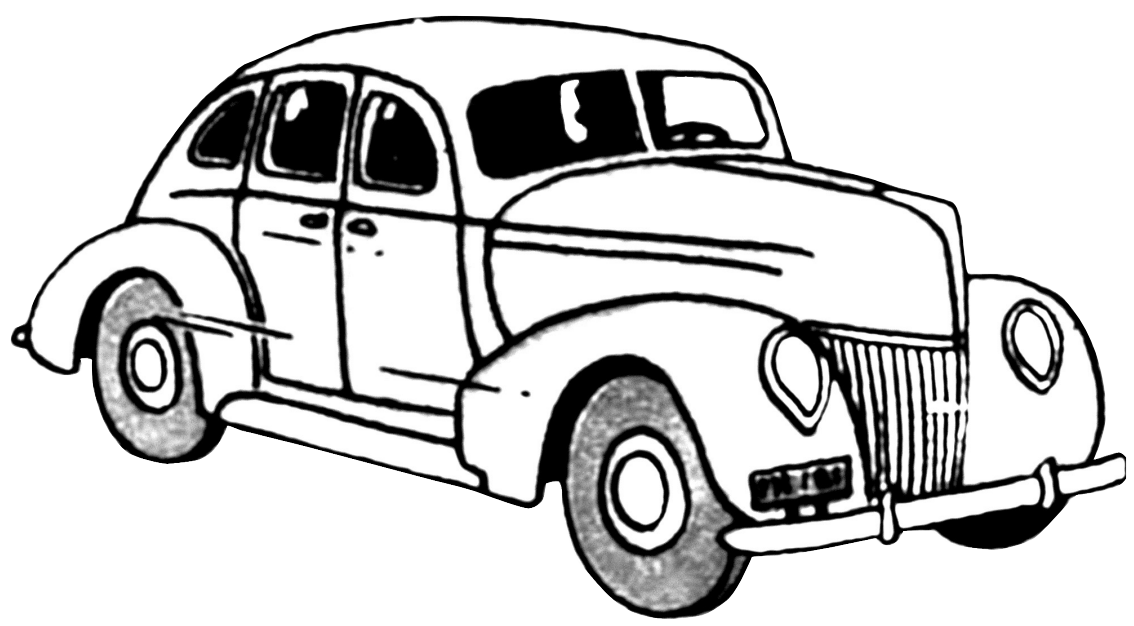



TRANS · núm. I6 2012

ENTREVISTA · 119-129

\section{Entrevista a la traductora Rocío de la Maya}

Angelo Nestore

Universidad de Málaga 
Rocío de la Maya es traductora especializada en cómic y novela gráfica, además de ser docente de la Facultad de Ciencias de la 120 Comunicación de la Universidad de Málaga. Entre sus trabajos, destaca la traducción al castellano de la obra gráfica de Alison Bechdel $^{\mathrm{I}}$ y de la novela gráfica The Acme Novelty Library del vanguardista autor norteamericano Chris Ware. Tener el privilegio de escuchar su experiencia directa resulta crucial a la hora de sacar a la luz elementos significativos que conciernen al proceso de traducción del cómic, un género artístico y literario en auge hoy en día. Asimismo, se arrojará luz sobre elementos propios de esta modalidad de traducción y se facilitará una información valiosa para todas aquellas personas que quieran abordar la traducción del cómic tanto desde un punto de vista profesional como teórico. A Rocío de La Maya mi más sincero agradecimiento.

En I986 Roberto Mayoral, Dorothy Kelly y Natividad Gallardo desarrollan el concepto de traducción subordinada, que incluye el doblaje, la traducción simultánea de películas, la traducción de textos publicitarios y de cómics. En su célebre articulo afirman que «desde el momento en que la traducción no sea únicamente de textos escritos, sino que estos estén en relación con otros medios (imagen, música, lengua oral, etc.) la tarea del traductor se ve complicada y a la vez limitada (o subordinada) por estos»². Desde su punto de vista, ¿̨es correcto

Lesbiana, activista, feminista y de izquierdas: así se define Alison Bechdel, autora de las novelas gráficas Fun Home $\mathrm{y}_{\dot{b}}$ Eres mi madre? y de los personajes que poblaron las viñetas de la serie de cómics titulada Dykes to Watch Out For (Unas bollos de cuidado, traducido por Rocío de la Maya). Desde los años 8o, sus publicaciones han aportado un cambio radical a la historia del cómic norteamericano, haciendo que ella se convirtiera en portavoz del movimiento contracultural.

2 R. Mayoral, D. Kelly y N. Gallardo, «Concepto de traducción subordinada (cómic, cine, canción, publicidad). hablar de una subordinación del texto a la imagen en el caso del cómic?

Según el cómic del que estemos hablando. En realidad no todos los autores son tan equilibrados y no sé si esto sería lo perfecto. Al principio diría que Ware es el artista más equilibrado en este sentido, desde luego, todo le urge a expresar de una manera perfecta: imagen, texto, maqueta. Hay, sin embargo, otros autores más desequilibrados, por ejemplo la propia Alison en su dibujo, pero yo creo que un texto inmenso no necesita tanta imagen que lo soporte, no es tan urgente esa comunicación. De alguna manera sucede como en el cine, supongo, cuantos más estímulos te vengan hacia la idea que quieres comunicar, más te acercarás a la comunicación total. Pero creo que es una idealización, hay textos más brillantes que su dibujo, y precisamente por eso es perfecto, $\mathrm{y}$ al revés.

Usted es profesora en la facultad de Ciencias de la Comunicación. ¿̇Hasta que punto sus conocimientos teóricos le han ayudado a traducir cómics? ¿Cree que hace falta una formación específica para traducir cómic, teniendo en cuenta la evolución que está viviendo en estos últimos años?

Los conocimientos que adquirimos a lo largo de nuestra vida nos sirven para toda labor intelectual que se realice $y$, en este sentido, $\mathrm{mi}$ formación teórica, tanto de la imagen fija como de la imagen secuencial, me ayudan a valorar el cómic desde una perspectiva más amplia. De todas formas, creo que una de las cosas más interesantes del mundo literario es el reciclaje, que pasa por poner en contacto las cosas que

Perspectivas no lingüísticas de la traducción (I)», en F. Fernández (ed.), Pasado, presente y futuro de la lingüistica aplicada en España. Actas del III Congreso Nacional sobre Lingüistica Aplicada. Valencia, Servicio de Publicaciones, I986, pp. 95-IO5. 
sabes. La literatura está llena de mundo, así que hay que estar en el mundo. No solo es un conocimiento intelectual desde un punto de vista más abstracto, sino de la cultura y de la calle, del entorno de cada país. Lo superficial también es mundo y el escritor utiliza todos los elementos de su época para contar cuanto más sepas de todo mejor comprenderás al autor y a su momento.

Respecto a la segunda pregunta, en mi caso fue al revés, primero empecé a traducir cómics y después (y por esta misma razón) me metí de lleno en el mundo del cómic. De todas formas, entre la traducción de novela gráfica y otro tipo de textos literarios no hay demasiada diferencia si dejamos a un lado la cuestión formal (espacio, imagen, etc.). Hoy por hoy resulta muy interesante contrastar la literatura tradicional con la novela gráfica: preferencias, intereses, prejuicios. Creo percibir una cierta relajación en la novela gráfica con respecto a la trascendencia que se presume en toda obra de arte, eso es un soplo de aire fresco que trato de mantener en mis propias traducciones.

Por otra parte, creo que toda formación es interesante para dedicarse a cualquier labor intelectual y artística, y el cómic no es más que un ejemplo. Cuanto más se conozca, más guiños se hallarán en cualquier obra. La formación específica es un engaño americano, hay que saber de todo.

¿Cree que la enseñanza en el grado y en el postgrado de la traducción de cómics es importante para la formación de futuros traductores? En caso afirmativo, ¿̇en qué sentido?

Toda formación es importante, pero no debe ser desligada de la traducción en general, ni de la filología en particular. Sin embargo, la traducción de cómics implica bastantes especificaciones y problemas añadidos que no se tienen en la traducción en general: el espacio que ocupa el texto, la longitud de un idioma con respecto a otro, las onomatopeyas, el lenguaje no escrito expresado a través del color y el dibujo. Es un trabajo bastante platónico, puesto que la imitación es lo más importante según veía Platón la obra de arte (una imitación perfecta de la realidad). Cuanto más se parezca un cómic a su original, mejor.

¿Cómo ha llegado a la traducción en general y a la de cómic en particular?

Fue por azar, o más bien fue un engaño al azar. En realidad, lo más interesante de mis inicios fue la «necesidad»: el descubrimiento de Alison Bechdel fue crucial en todo este proceso. Desde que tuve la oportunidad de conocer su obra sentí que tenía que dar voz en español a una escritora desconocida en nuestro país, cuya ideología y política venían de vuelta (ironía, sarcasmo) de un mundo que nosotros ni siquiera habíamos recorrido aquí. Mi colaboración con Mondadori viene a través de la propia Alison y de su novela gráfica Fun Home, y desde entonces colaboro con ellos y otras editoriales en la traducción de cómics. No dejo de aprender en este campo, a través de esta editorial llegaron Chris Ware, Daniel Clowes, David Small..., y recientemente he tenido la oportunidad de trabajar con el editor portugués Manuel Caldas en la traducción al español de un cómic clásico de los años 5o, The Cisco Kid.

Usted acaba de citar a Chris Ware, un autor que se caracteriza por subvertir en sus obras la lógica convencional de la narración y de la descripción en el cómic; al extender las posibilidades narrativas, crea un lenguaje unico que pone en tela de juicio el propio papel del público lector y, por lo tanto, del traductor. ¿Está de acuerdo? ¿Qué dificultades se presentaron a la hora de traducir su obra? 
Sí, estoy de acuerdo. Creo que Ware es el genio del cómic, cuya facilidad narrativa le permite contar de todas las formas posibles, tanto que a medida que lo traducía yo sola pegaba carcajadas, me admiraba, sentía la experiencia estética de su obra. Su descaro a la hora de contar crea escuela, estoy convencida.

Por supuesto que genera dificultades, tiene mil voces y mil registros, a ratos es el tierno poético, otros es el lacónico friqui de habitación, a ratos es el vendedor de crecepelo americano, a ratos es el que destroza toda la sociedad de consumo, a ratos es el cínico soez... todos esos registros tienen su intención a la hora de hacer todo un corpus, todo un libro, toda una idea.

Además de Chris Ware, David Small y Alison Bechdel, ¿qué cómics ha traducido? ¿Cuál le ha entrañado el mayor reto? ¿Por qué?

He traducido también Tóxico de Charles Burns, Wilson y $M r$. Wonderful de Daniel Clowes y, como comenté antes, el primer libro de la serie The Cisco Kid, pero, quizás, la que me ha parecido más compleja ha sido Alison Bechdel por sus miles de matices culturales, sociales, políticos, sexuales. Es de una complejidad brutal. Todo un reto siempre.

Conforme se publican más cómics traducidos por usted, ¿nota un aumento de encargos por parte de las editoriales?

Ojalá el mundo editorial fuese tan fácil... No, lo único que noto es que las editoriales con las que trabajo confían en mí. El mundo de la traducción no es demasiado respetado, no preocupa demasiado que el traductor sepa o no minimizar el descuento cultural que supone cambiar de un idioma a otro, ni aliarse con el contexto del autor, ni con todo su corpus.
Desde su punto de vista, ¿̇tiene el número de encargos de traducción alguna relación con el auge que está viviendo actualmente la novela gráfica en nuestro pais?

El auge de la novela gráfica tiene que ver también con una profusión de editoriales más modestas y con la entrada de las grandes editoriales en el mundo del cómic, pero cada editorial confía en sus traductores, en sus maquetadores, etcétera. No es fácil que te «fichen» de una editorial a otra.

¿Cuáles son sus autores de cómics preferidos? ¿Los lee en lengua original o en traducción?

Tengo predilección por Chris Ware (he tenido la oportunidad de traducir su obra Acme Novelty Library - Catálogo de Novedades $A C M E-$, publicada por Mondadori en mayo de 2009), creo que es un renovador, un artista único, un crítico y, sobre todo, es hijo de su tiempo. Necesitamos artistas en todas las disciplinas que sepan aportar una mirada sarcástica de todo, necesitamos que sepan descontextualizar para mirarlo todo desde afuera.

Los leo en el idioma original, desde luego, necesito saber qué se quiere decir y cómo. Aunque también leo cómics traducidos, por supuesto.

¿Qué opinión le merece la industria editorial del cómic en España?

Para mí aún es pronto para valorar una industria en la que no llevo mucho tiempo, pero tiene una gran trayectoria. Creo que hay muy buena intención a la hora de elegir y de mostrar, sobre todo es importante ver que va en aumento la cantidad de cómics publicados por editoriales importantes que gracias a éstas llegan con más facilidad a las librerías más importantes de las ciudades, y no sólo las especializadas en cómic. Es un sector prometedor $\mathrm{y}$ tiene editoriales 
magníficas como SinSentido, Norma, Astiberri, La Cúpula...

Hablando de editoriales españolas, ¿̨cuál ha sido la primera editorial en apostar por el trabajo de Alison Bechdel en España? ¿Cree que la obra de la autora es un reflejo del cambio que se está produciendo actualmente en el panorama del cómic con el éxito-moda de la novela gráfica (como en el caso de Persépolis)?

La primera editorial en publicar títulos de la serie Dykes to Watch Out For fue Egales, una editorial gay-lésbica fundada por las librerías Berkana de Madrid y Cómplices de Barcelona. En su momento fue una apuesta más política que comercial y, posteriormente, fue La Cúpula la que continuó la labor iniciada por Egales con la publicación de tres títulos más de la serie en español antes de que Mondadori se hiciese con los derechos de Fun Home, la primera novela gráfica de Bechdel.

La obra de Alison Bechdel es un cambio en general, no solo por la novela gráfica, sino por su apuesta propia. De cualquier forma este éxito-moda tiene que ver con un acercamiento formal al mundo literario, el autor de cómic ya no es un escritor de segunda sino que empieza a ser considerado como lo que es, un escritor (entre otras cosas). Esta diferencia les da una cierta frescura literaria a estos autores, son necesarios.

¿Cuál cree que va a ser la evolución de la novela gráfica? ¿Esa evolución está relacionada con los avances de la comunicación audiovisual, como el caso de Chico y Rita de Trueba y Mariscal o de Arrugas de Paco Roca?

La evolución de la novela gráfica pasa por este respeto del que hablaba antes, tendremos que ver a un escritor de cómic ganando un premio literario de importancia con cierta facilidad, tendremos que ver cómo se convierten en los intelectuales que de verdad son. Las apuestas son muchas y creo que meritorias para la imagen literaria de un país.

Por supuesto, cuantos más procesos de canalización de la información tenga una obra, más sencillo será aprehenderla. Quiero decir que la visualización de un texto es tan importante como lo que se diga, pero también más difícil. ¿Cómo poner al unísono texto y dibujo? Esta dualidad requiere un ritmo y una tensión, en este caso Chris Ware es un maestro.

¿Hasta qué punto influye el público lector a la hora de traducir una novela gráfica?

Mucho, el lector lo es todo en el mundo de la literatura. En realidad creo que todo escritor tiene un lector ideal en la cabeza, tratar de ser fiel a ese lector ideal es importante. Por otro lado en este país hay que traspasar la barrera esa de «yo no leía cómics de pequeño, así que ahora menos», pensando que un cómic no ha evolucionado nada desde aquellos entonces. La gente todavía desconoce un poco el concepto de novela gráfica.

Usted conoció en primer lugar los cómics de Alison Bechdel como lectora del texto original y, más tarde, fue quien propuso su traducción al castellano. Con respecto a su obra, ¿̇en qué aspectos le ha ayudado haber traducido un álbum de la serie Dykes to Watch Out a la hora de llevar a cabo la traducción de la novel gráfica Fun Home?

En todos los aspectos. Conocer a la Alison de Dykes to Watch Out For te da una idea general de su apuesta, esto no puede ser desligado de su novela gráfica. Son puntos como la ironía, el sarcasmo, la sutileza a la hora de hacer una crítica social, el papel de las lesbianas y su mundo, la crítica abierta al mundo superficial y falso de lo norteamericano, a un prototipo de 
personas. Alison es una observadora bastante tenaz.

124 A lo largo de la obra de Alison Bechdel, por ejemplo, aparecen numerosos términos relativos a la jerga lesbiana. ¿Cómo ha resuelto este problema léxico? $\dot{¿}$ Ha recurrido a un diccionario especializado para traducirlos?

No siempre, hay cuestiones que se ven en la calle, que se comentan. Hoy por hoy la jerga lesbiana es un poco más fácil de oír, todos sabemos lo que es un dildo y ser queer. Quiero decir, que ya no existe esta separación de mundos, y por tanto de jergas. ¿Hay un diccionario lesbianasespañol?3

A diferencia de su trabajo, en la versión italiana de Fun Home no se ha prestado particular atención a la rotulación, tanto que todas las notas y las páginas del diario se han traducido utilizando una tipografía predeterminada de ordenador. ¿Cree que esto puede afectar a la lectura del cómic? Según su opinión, ¿̇hasta qué punto la rotulación forma parte del significado?

Forma parte del significado, por supuesto. La labor del escritor del cómic es comunicarse con todo, mi labor como traductora es asemejarme y la labor del que rotula es hacer que ninguno de los anteriores pierda ningún ápice de realidad. En un cómic todo lo planteado tiene una intención, no podemos salirnos de esta intención, porque detrás de la intención va toda la posibilidad de comunicarse. Aquí soy muy puntillosa y la editorial también.

3 En 2008 apareció en España un diccionario de términos queer, se trata del Diccionario gay-lésbico: vocabulario general y argot de la homosexualidad de Félix Rodríguez González publicado por la editorial Gredos.
Aunque Alison Bechdel habia declarado en una entrevista ${ }^{4}$ que su siguiente entrega iba a centrarse en sus relaciones sentimentales, en mayo de 2012 se publicará su segunda novela gráfica titulada Are You My Mother?, que representa la continuación «natural» de Fun Home. ¿Hasta qué punto cree que el éxito editorial de su primer libro ha influido en la plasmación artística del segundo?

Estoy convencida de que es una continuación intencionada desde un punto de vista comercial, está en su mejor momento y es consciente de ello. Desde un punto de vista económico la serie de Dykes to Watch Out For no es tan rentable, entre otras cosas porque se dirige a un lector más especializado y minoritario.

Tiene en perspectiva traducir Are You My Mother?5, ¿usted contactó con la editorial o es Mondadori quien cuenta con usted como traductora?

Sí, Mondadori me acaba de encargar la traducción, que se editará en España a finales de año (creo que la edición en Estados Unidos saldrá en el mes de mayo). Fue la editorial la que se puso en contacto conmigo después de adquirir los derechos.

En el imaginario colectivo a menudo se ha considerado la norma hegemónica como un discurso monolitico y poco flexible, en contraposición a la versatilidad que caracterizan las fuerzas subversivas. Sin embargo, en palabras de Stuart Hall ${ }^{6}$, «la

4 Entrevista integral: genderacrossborders.

com/2010/o2/23/a-conversation-with-alison-bechdel/ [consultado: 23 de enero de 20I2]

5 La nueva novela gráfica de Alison Bechdel, Are You My Mother?, fue publicada en Estados Unidos el día 3 de mayo de 2012 por la editorial Jonathan Cape. El 6 de septiembre del mismo año Mondadori saca a luz la versión española ¿Eres mi madre? [N. de los Eds.]

6 S. Hall, «Old and New Identities, Old and New Ethnicities» en Anthony D. King (ed.) Culture, Globaliza- 
hegemonía no es la desaparición o destrucción de la diferencia. Es la construcción de la voluntad común por medio de la diferencia». En otras palabras, produce una subjetividad sometida a los valores de la cultura que impone.7 Por lo tanto, el discurso dominante demuestra una gran plasticidad, pues engendra subjetividades $y$, a la vez, transforma cualquier posibilidad en un hipotético beneficio. Bajo esta perspectiva y en relación a las preguntas anteriores, ¿debería una artista que vebicula unos ideales subversivos doblegarse a las leyes del mercado?

No, si fuese así acabaríamos todos subyugados por la moda. Es el artista quien debe salirse de esa prisión con grilletes que es toda sociedad; si perdemos la posibilidad de pensar, para preferir hacer como que pensamos nos va a ir muy mal. El ejemplo es tan contemporáneo que asusta, aunque no creo para nada que sea una cuestión solamente actual. El artista debe remover conciencias, debe cuestionárselo todo, no puede perder el privilegio de inventar un mundo diferente una y otra vez.

Me parece que éste es el caso de Alison Bechdel: el público lector se enfrenta a un texto experimental $y$ rompedor, cuyo mensaje politico se alinea con las matrices de la Teoría Queer. La personalidad española más influyente en este ámbito es sin duda la filósofa Beatriz Preciado. ¿Existe también en el ámbito de la novela gráfica en nuestro país un filón artístico queer independiente o nos encontramos aún en una fase embrionaria y la novela gráfica Alicia en un mundo real de Isabel Franc

tion and the New World-System. Contemporary Conditions for the Representation of Identity, Nueva York, Department of Art and Art History, 1991, p. 58.

7 «La producción no sólo produce un objeto para el sujeto, sino también un sujeto para el objeto», como afirmó K. Marx en Introducción a la crítica de la economía política. (escrito en 1857), trad. Jesús Castellote López. México, Fondo de Cultura Popular, 1970, pp. 29 y ss. y Susanna Martín representa, por ejemplo, sólo un timido paso en este sentido?

Yo creo que estamos en una fase embriona125 ria, desde luego no es una corriente demasiado trabajada en el mundo de la literatura española en general. Yo creo que hay que tener en cuenta que todavía no ha calado demasiado en nuestra sociedad, más allá de la filosofía y la militancia.

En relación con la pregunta anterior, ¿̇la traducción representa un elemento catalizador para la difusión de la Teoría Queer? ¿Es usted consciente de esta responsabilidad politica a la hora de traducir novelas gráficas, como en el caso de la obra de Alison Bechdel?

Por supuesto. De hecho hace poco he leído el Corydon de André Gide que es muy iluminador en este sentido. Ponía un ejemplo precioso de la traducción de Whitman (el gran poeta homosexual americano): the friend es traducido por el bienpensante como "la amiga», love en el contexto masculino por amistad y lo que es mucho peor para destrozar toda la idea whitmaniana, en la frase the beaving sea («el mar que se levanta») siente el traductor la horrorosa necesidad de añadir "como un seno", para que lo heterosexual de Whitman sea completamente ortodoxo. Esto es una canallada, no podemos inventarnos al autor como hubiésemos querido que fuese por nuestros prejuicios sociales, el autor es lo que es y punto.

Desde un punto de vista más práctico, me gustaría preguntarle sobre los principales problemas que puede afrontar en la traducción y cómo los resuelve. ¿Ha tenido alguna vez problemas de tiempo?

He tenido todo tipo de problemas, es esto realmente lo más divertido del asunto. Cada escritor tiene su microcosmos y hay que adaptarse constantemente a él, cada cómic es un reto. 
Si no hubiese habido problemas no tendría gracia. Problemas de tiempo, de encajar un texto en un espacio, problemas con el color, problemas con las tipografías, problemas con cómo decir esta frase tan visual del mismo modo en otro idioma. A los problemas de cualquier traductor (que no son pocos) se añaden los problemas del espacio y del juego visual (globos, viñetas, etc.).

Hablando de problemas del espacio y del juego verbal, ¿̇que dificultades tiene a la hora de traducir las onomatopeyas? ¿Consulta algún diccionario, como por ejemplo el Diccionario de onomatopeyas del cómic ${ }^{8}$ de Luis Gasca y Román Gubern?

Lo he usado en algunas ocasiones para aclarar conceptos, pero es más bien un catálogo, una muestra, un listado de onomatopeyas en su idioma original, sin traducir. De todas formas, creo que en las onomatopeyas también hay modas, así que su traducción es bastante difícil y, yo diría, casi personal por parte del traductor muchas veces.

¿Las editoriales con las que ha colaborado le han impuesto restricciones a la hora de traducir? ¿Quién suele ser su interlocutor? ¿Ha tenido corrector de estilo? ¿Ha hecho cambios sugeridos por la editorial?

En el caso de Mondadori, que es con quien más he trabajado, nunca me han impuesto restricciones, trabajan como una máquina perfectamente engrasada, saben qué le compete a quién.

He tenido interlocutores varios, aunque mi relación directa es con el equipo de redacción. También tengo contacto con el equipo de producción para determinar cuestiones relativas al acabado final del cómic, aunque esto pertenece

\footnotetext{
8 L. Gasca y R. Gubern, Diccionario de onomatopeyas del cómic, Madrid, Cátedra, 2008.
}

más al ámbito de la maquetación y rotulación.

Sí, desde luego que he tenido corrector de estilo, un traductor necesita que lean sus textos desde otra perspectiva. En muchos casos ha sido aleccionador.

Como he comentado, la editorial y yo trabajamos codo a codo con la idea de perfeccionar el cómic cada vez, así que cuando me sugieren cosas casi en un Ioo\% es para mejorar el producto.

¿Suele consultar otras traducciones ya publicadas? En los cómics es posible hallar a menudo citas de otros autores; en el caso de Fun Home, por ejemplo, aparecen citas de Fitzgerald, Joyce, Henry James, Shakespeare, Proust, Camus y Wallace Stevens. ¿Qué estrategia de traducción suele emplear?

En los casos en los que la lengua originaria era el francés, decidimos de acuerdo con la editorial evitar la traducción de la traducción, así que recurrimos a textos publicados previamente en castellano en editoriales importantes. No concibo la traducción de un autor previamente traducido a otra lengua, no tiene mucho sentido.

Como asevera Scott $M c C l o u d$ en su libro Entender el cómic, ${ }^{9}$ se suele afirmar que palabras e imágenes juntas producen algo mediocre o simplista. ¿Piensa que uno de los objetivos de Alison Bechdel ha sido precisamente intentar cuestionar este lugar común? ¿Podría citar a otras autoras y otros autores de cómics que persiguen el mismo objetivo?

Creo que se confunde aquí lo sencillo con lo simple. Si tiene dibujos es más fácil, no sé si estoy muy de acuerdo con esta afirmación. Comprendo que es verdaderamente difícil que ambas partes (imágenes y palabras) vayan al

9 S. McCloud, Entender el cómic. El arte invisible, trad. de Enrique Abulí. Bilbao, Astiberri, I995. 

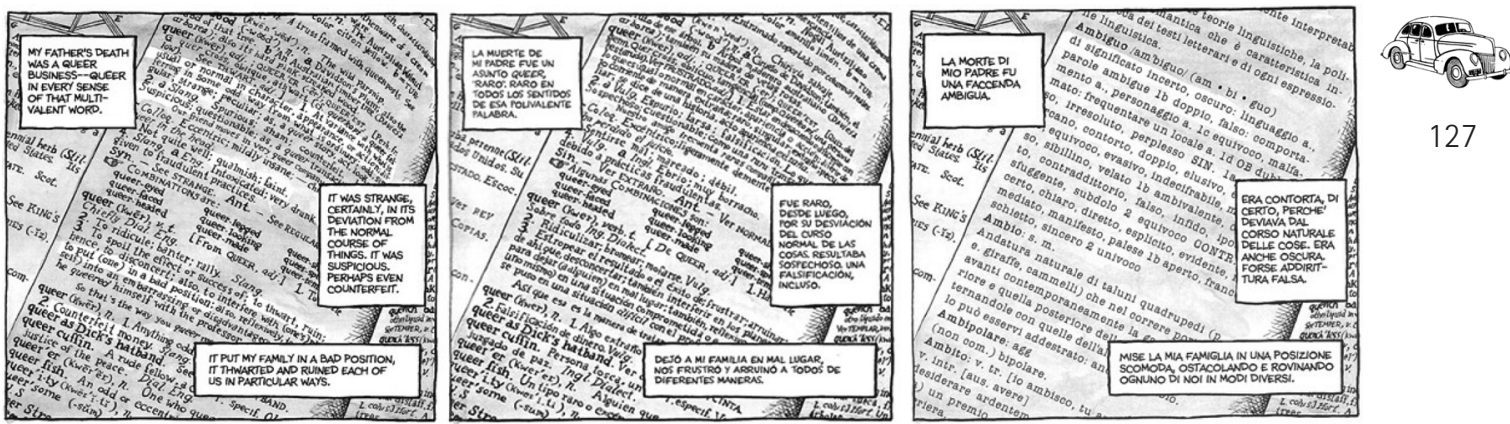

127

Viñeta extraída de Fun Home en su versión original, española e italiana

unísono, pero, cuando esto es así, ¿es fácil?, ¿fácil para quién?, ¿para qué? Desde luego Alison no es la única que lo cuestiona, hay muchos escritores de cómic contemporáneos que lo subvierten en mayor o menor medida, como los citados Chris Ware o Daniel Clowes.

${ }_{\dot{C}}$ Cree que es posible subvertir normas politicosociales a través del cómic?

Creo que no hay que pensar sobre las cosas desde los extremos. Mientras se dé la comunicación con el público lector y este se quede reflexionando un segundo con la crítica puesta en la frente, habrá merecido la pena. Se trataba de eso.

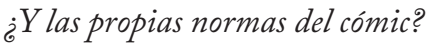

Por supuesto que sí. Si un autor respeta las fronteras ortodoxas que le son dadas, ha muerto. Hay que romper, por supuesto.

\section{¿Suele elegir usted la cubierta de los libros?}

Este es un aspecto que siempre decide la editorial, al menos en los cómics que he traducido hasta el momento. Otra cuestión bien distinta es el título, en este caso solemos consensuarlo.

¿Qué herramientas informáticas deberian apren- der a utilizar aquellos traductores que quieren especializarse en la traducción del cómic? ¿Es suficiente con saber manejar un editor de texto?

Yo creo que tampoco son muy necesarias demasiadas herramientas informáticas, simplemente manejar archivos pdf, tifs, etcétera. Muchas veces hay texto en partes que no se ven a simple vista o que luego no terminan apareciendo en el cómic, o que simplemente se cortan y hay que traducirlos también. Un cómic, a veces, va más allá del corte de la imprenta.

Teniendo en cuenta la especificidad de la traducción del cómic, ¿̇cómo se suelen establecer las tarifas de traducción? ¿Se suele cobra por viñeta, por palabra o por página?

Depende de las editoriales. Algunas establecen tarifas fijas por página, independientemente de la cantidad de texto que haya que traducir. En otros casos el cálculo de la tarifa se hace a partir de los caracteres con espacios que contenga el documento final que se entrega a la editorial.

Ante una considerable duda sobre la comprensión del texto original, ¿לba contactado alguna vez con la autora o autor para precisar una aclaración? 
¿Cuenta también con el apoyo de comunidades de traductores online?

No, casi nunca estoy en contacto con ellos, 128 lo que me parece terrible. Es la editorial la que gestiona todas esas cuestiones, eso se lleva muchas veces algún que otro significado por el aire.

Sí, cuento con todos los apoyos posibles, hay gente muy interesante en la red. A veces son más exactos que el mejor traductor del mundo.

El espacio en el cómic se articula mediante convenciones especificas como bocadillos, didascalias y viñetas. Estos elementos influyen en todo momento la labor de traducción, por ende ipodría explicarme cómo se planea el trabajo con la persona encargada de la rotulación? ¿Ha tenido que proporcionar alguna vez una segunda traducción por problemas de rotulación?

Algunas veces. Trabajar con el rotulador es muy importante, el espacio es crucial. En principio se plantea una traducción, acorde a la idea de que el español ocupa más espacio que el inglés y acorde a la idea de que hay que tener en cuenta la concisión de forma que toda la idea completa quepa en el bocadillo, por ejemplo. Después el rotulador o el maquetador te sugieren algún cambio, alguna precisión, pero si lo haces bien no suelen ser muchos. Aquí la experiencia es un grado para no tener que traducir muchas veces.

Usted suele trabajar con la rotuladora Maria EloyGarcía. ¿Podría contarme de qué forma colaboran y cómo organizan el trabajo?

La traducción es el primer paso, después viene la rotulación. Si hay algún problema de espacio, a pesar de que lo tengo muy en cuenta a la hora de traducir, la rotuladora me indica los textos que resultan demasiado extensos y se vuelven a traducir de una manera más concisa.
Cuando trabajas siempre con la misma persona es más fácil y eficiente el trabajo.

El espacio del cómic plantea también problemas a la hora de traducir el estilo: el texto contenido en los bocadillos suele reproducir el discurso oral. ¿Quéproblemas ha encontrado a la hora de conferir al productor del texto original (en la mayoría de los casos norteamericano) la actitud y los rasgos lingüísticos de un miembro de la comunidad de la lengua de llegada?

Normalmente la diferencia es que el discurso en los bocadillos es más directo, más rápido, más asertivo y el «metatexto» (si se puede llamar así) que subyace en el interior de la viñeta es un guiño trascendente, irónico, mordaz, que complementa todo un discurso. En un cómic es tan importante lo que se dice como lo que se calla, porque todo se cuenta. En el caso de Clowes, se cuenta hasta la miseria que vive en todo yo que se precie, ya sea por un alter ego que habla, ya sea por sus pensamientos directos; hasta en el dibujo el cambio se aprecia por lo caricaturesco cuando habla uno u otro personaje, que por otro lado es el mismo.

Teniendo en cuenta que, evidentemente, lo ideal sería traducir tanto la forma como el contenido sin que ninguno de ambos interfiriera en el otro, ¿ha tenido alguna vez que sacrificar el uno en pro del otro? ¿Qué criterios ha empleado?

Por supuesto. He sacrificado ambas, unas veces la forma para que el contenido quedara lo menos alterado posible, hay que tener en cuenta también que la forma es bastante exigente en un cómic. Por otro lado si la forma se altera, el contenido ya no puede ser el mismo, sino una recreación.

¿Ha estado en contacto con otros tipos de textos en cuanto a traducción se refiere? 
Sí, ha habido algún otro. De hecho, en uno de ellos traduje prosa y poesía a la vez. Considero que la poesía es la traducción más difícil de todas, porque no es lo mismo decir que sugerir mil cosas teniendo en cuenta la forma y el fondo. El texto era de la época surrealista, lo que lo hizo enormemente difícil. Todo reto es un universo lleno de desagravios y alegrías.

Para terminar, ¿algún consejo a jóvenes traductoras y traductores que quieran dedicarse a la traducción del cómic?

Es un mundo apasionante, se lo recomendaría a cualquiera, joven o viejo. Empezaría, desde luego, leyendo bastante cómic, traducido o no. Me metería de lleno en un mundo narrativo que está repleto de grandes obras de arte y que habla mucho de la idea de futuro de una sociedad camino de ser su propia caricatura.

RECIBIDO Y VERSIÓN FINAL: DICIEMBRE DE $20 I I$ ACEPTADO: FEBRERO DE $20 \mathrm{O} 2$ 